\title{
Erratum to: Habitat selection disruption and lateralization impairment of cryptic flatfish in a warmer, hypercapnic, and contaminated ocean
}

\author{
Eduardo Sampaio $^{1,3}\left(\mathbb{D} \cdot\right.$ Ana Luísa Maulvault ${ }^{1,2,3}$ - Vanessa M. Lopes ${ }^{3}$. \\ José R. Paula $^{3} \cdot$ Vera Barbosa $^{1} \cdot$ Ricardo Alves $^{1} \cdot$ Pedro Pousão-Ferreira $^{1}$. \\ Tiago Repolho ${ }^{3} \cdot$ António Marques ${ }^{1,2} \cdot$ Rui Rosa $^{3}$
}

Published online: 16 November 2016

(C) Springer-Verlag Berlin Heidelberg 2016

Erratum to: Mar Biol (2016) 163:217

DOI 10.1007/s00227-016-2994-8

Due to inaccurate terminology, the word "acid" should be replaced by "hypercapnic" in the title.

Moreover, in order to comply with SI unit standards, $\mathrm{pCO}_{2}$ units across the manuscript should be read as " $\mu$ atm", instead of "ppm".

The online version of the original article can be found under doi:10.1007/s00227-016-2994-8.

Eduardo Sampaio

edusilvasampaio@gmail.com

Divisão de Aquacultura e Valorização (DivAV), Instituto Português do Mar e da Atmosfera (IPMA, I.P.), Av. Brasília, 1449-006 Lisbon, Portugal

2 Interdisciplinary Centre of Marine and Environmental Research (CIIMAR), University of Porto, Rua das Bragas, 289, 4050-123 Porto, Portugal

3 MARE - Marine Environmental Science Centre, Laboratório Marítimo da Guia, Faculdade de Ciências da Universidade de Lisboa, Av. Nossa Senhora do Cabo 939, 2750-374 Cascais, Portugal 